\title{
Mass transfer and thermodynamic modeling of carbon dioxide absorption into MEA aqueous solution
}

\author{
Ahad Ghaemi \\ Iran University of Science and Technology, Department of Chemical, Oil and Gas Engineering, P.O. Box: 16765-163, \\ Tehran, Iran \\ "Corresponding author: e-mail: aghaemi@iust.ac.ir
}

\begin{abstract}
In this research, thermodynamic and absorption rate of carbon dioxide in monoethanolamine (MEA) solution was investigated. A correlation based on both liquid and a gas phase variable for carbon dioxide absorption rate was presented using the $\pi$-Buckingham theorem. The correlation was constructed based on dimensionless numbers, including carbon dioxide loading, carbon dioxide partial pressure, film parameter and the ratio of liquid phase film thickness and gas phase film thickness. The film parameter is used to apply the effect of chemical reactions on absorption rate. A thermodynamic model based on the extended-UNIQUAC equations for the activity coefficients coupled with the Virial equation of state for representing the non-ideality of the vapor phase was used to predict the $\mathrm{CO}_{2}$ solubility in the $\mathrm{CO}_{2}-\mathrm{MEA}-\mathrm{H}_{2} \mathrm{O}$ system. The average absolute error of the results for the correlation was $6.4 \%$, which indicates the accuracy of the proposed correlation.
\end{abstract}

Keywords: modeling; $\mathrm{CO}_{2}$; absorption rate; extended UNIQUAC; MEA solution.

\section{INTRODUCTION}

In the past few years, the huge emission of greenhouse gases caused by human has become one of the most discussed environmental issues around the world. $\mathrm{CO}_{2}$ is the main greenhouse gas and its reduction is essential in terms of environmental, energy and economics. This duty is an interesting research on $\mathrm{CO}_{2}$ reduction where novel energy-efficient processes are essential. Reactive absorption of $\mathrm{CO}_{2}$ with amine solutions is appropriate technology from technical, economic and environmental points of view ${ }^{1,2,3}$. A wide variety of amines has been used industrially for a number of years ${ }^{2,4-6}$. Chemical absorption of $\mathrm{CO}_{2}$ with amines as a solvent has been used in a large variety of industries over the years ${ }^{7}$. Natural gas sweetening and production of methanol and ammonia are among the biggest industries that are utilizing chemical absorption of $\mathrm{CO}_{2}$ with amine solutions $^{\mathbf{8}, 9,10}$. In addition, the use of the alkanolamines process for $\mathrm{CO}_{2}$ absorption from the exhaust gas of cement factories and power plants has received extensive interest recently because of the need for mitigation of greenhouse gas emissions ${ }^{11,12}$. The absorption of $\mathrm{CO}_{2}$ into reactive solvents is one of the most promising technologies for $\mathrm{CO}_{2}$ capturing ${ }^{13}$. Amine aqueous solutions have been used wide-spreading for the removal of $\mathrm{CO}_{2}$ from natural gas and flue gas via reactive absorption ${ }^{2}$. Among the industrially utilized alkanolamines, MEA is the most widely used absorbent for $\mathrm{CO}_{2}$ absorption because of its properties to $\mathrm{CO}_{2}$ capture such as a high absorption capacity, fast reaction kinetics, and high solubility ${ }^{14,15}$. Due to its high reactivity with $\mathrm{CO}_{2}$, MEA is the main solvent for $\mathrm{CO}_{2}$ capture in post-combustion processes. MEA as a primary amine has an ability to remove a high amount of $\mathrm{CO}_{2}$, even at the low $\mathrm{CO}_{2}$ concentrations ${ }^{16}$. It can effectively remove a high amount of gas removal due to a high reaction rate. If the process is extended, an economic and environmental global impact will occur. In the recent decades, several works have been carried out to investigate the kinetics and reaction mechanism of $\mathrm{CO}_{2}$ absorption into MEA solution ${ }^{17-20}$. Nevertheless, there is still a controversy regarding the thermodynamics and mass transfer of $\mathrm{CO}_{2}$ in MEA solution.

In this work, based on the Etemad et al. approach ${ }^{21}$, a general correlation has been presented to calculate the mass transfer flux of $\mathrm{CO}_{2}$ into MEA solutions. The correlation is applicable for a wide range of operating conditions at all absorption equipment. In the presented correlation, the influence of chemical reactions, $\mathrm{CO}_{2}$ loading, $\mathrm{CO}_{2}$ partial pressure, the film thickness of phases and ratio of $\mathrm{CO}_{2}$ diffusion coefficients of absorption rate were considered. Also, the effect of molecular and ionic species on $\mathrm{CO}_{2}$ absor into aqueous solutions, all the parameters and variables influencing on mass transfer flux are provided in the following equation:

$N_{\mathrm{CO}_{2}}=f\left(k, k_{L}, D_{G}, D_{L}, \delta_{G}, \delta_{L}, P_{C_{2}}, P_{t}, C_{C_{2}}, C_{a \text { mine }}\right)$

The variables are including both liquid and gas phases. The variables with dimensions and units are given in Table 1.

Using the $\pi$-Buckingham dimensionless approach, the dimensionless parameters in the $\mathrm{CO}_{2}$ reactive absorption processes is presented as eq. $2^{21}$.

$\frac{N_{\mathrm{CO}_{2}}}{k_{L}\left(\left[\mathrm{CO}_{2}\right]^{i}-\left[\mathrm{CO}_{2}\right]^{b}\right)}=f\left(\frac{P_{\mathrm{CO}_{2}}}{P}, \frac{D_{g}}{D_{L}}, \frac{\delta_{g}}{\delta_{L}}, \quad M, \alpha\right)$

Finally, the relationship between dimensionless parameters obtained as indicated in eq. 3 .

$\frac{N_{\mathrm{CO}_{2}}}{k_{L}\left(\left[\mathrm{CO}_{2}\right]^{i}-\left[\mathrm{CO}_{2}\right]^{b}\right)}=a .(S h)^{b}(M . \alpha)^{c}\left(\frac{D_{G}}{D_{L}}\right)^{d}\left(\frac{\delta_{G}}{\delta_{L}}\right)^{e}\left(\frac{P_{C O_{2}}}{P_{t}}\right)^{f}\left(\frac{1}{\alpha}\right)^{g}$

The correlation coefficients are depending on the absorption system and operating conditions. In equation 3 , $\left[\mathrm{CO}_{2}\right]^{i}$ is the equilibrium molecular concentration of carbon dioxide in the interface. Since the film model is assumed, the Sherwood number would be 1 and it will be eliminated from the dimensionless list ${ }^{21}$. By simplifying the term of loading and Sherwood number, mass flux correlation is:

$N_{C O_{2}}=a \cdot k_{L}\left(\left[\mathrm{CO}_{2}\right]^{i}-\left[\mathrm{CO}_{2}\right]^{b}\right)(M)^{c}(\alpha)^{d}\left(\frac{P_{\mathrm{CO}_{2}}}{P_{t}}\right)^{e}\left(\frac{\delta_{G}}{\delta_{L}}\right)^{f}\left(\frac{D_{G}}{D_{L}}\right)^{g}$ 
Table 1. Effective variables of carbon dioxide absorption process and their units

\begin{tabular}{|c|c|c|}
\hline Parameter & Unit & Dimension \\
\hline Mass transfer flux [ $\left.\mathrm{N}_{\mathrm{CO} 2}\right]$ & $\mathrm{mol} /\left[\mathrm{m}^{2} \cdot \mathrm{s}\right]$ & $\mathrm{ML}^{-2} \mathrm{~T}^{-1}$ \\
\hline $\begin{array}{l}\text { Reaction rate coefficient- } \\
\text { Second order [k] }\end{array}$ & $\mathrm{m}^{3} /[\mathrm{mol} \cdot \mathrm{s}]$ & $\mathrm{L}^{-3} \mathrm{M}^{-1} \mathrm{~T}^{-1}$ \\
\hline $\begin{array}{l}\text { Liquid mass transfer } \\
\text { coefficient }\left[k_{L}\right]\end{array}$ & $\mathrm{m} / \mathrm{s}$ & $\mathrm{LT}^{-1}$ \\
\hline $\begin{array}{l}\text { Diffusion coefficient of } \mathrm{CO}_{2} \\
\text { in gas }\left[D_{G}\right]\end{array}$ & $\mathrm{m}^{2} / \mathrm{s}$ & $\mathrm{L}^{2} \mathrm{~T}^{-1}$ \\
\hline $\begin{array}{l}\text { Diffusion coefficient of } \mathrm{CO}_{2} \\
\text { in liquid [ } \mathrm{D}_{\mathrm{L}} \text { ] }\end{array}$ & $\mathrm{m}^{2} / \mathrm{s}$ & $L^{2} T^{-1}$ \\
\hline Thickness of gas film $\left[\delta_{\mathrm{G}}\right]$ & $\mathrm{m}$ & $\mathrm{L}$ \\
\hline Thickness of liquid film $\left[\delta_{L}\right]$ & $\mathrm{m}$ & L \\
\hline $\begin{array}{l}\text { Partial pressure of } \mathrm{CO}_{2} \text { in } \\
\text { gas phase }\left[\mathrm{P}_{\mathrm{CO} 2}\right]\end{array}$ & $\mathrm{Pa}$ & $\mathrm{ML}^{-1} \mathrm{~T}^{-2}$ \\
\hline Total pressure $\left[\mathrm{P}_{\mathrm{t}}\right]$ & $\mathrm{Pa}$ & $\mathrm{ML}^{-1} \mathrm{~T}^{-2}$ \\
\hline $\begin{array}{l}\text { Concentration of } \mathrm{CO}_{2} \\
{\left[\mathrm{C}_{\mathrm{CO} 2}\right]}\end{array}$ & $\mathrm{mol} / \mathrm{lit}$ & $\mathrm{ML}^{-3}$ \\
\hline $\begin{array}{l}\text { Concentration of amine } \\
{\left[\mathrm{C}_{\text {amine }}\right]}\end{array}$ & $\mathrm{mol} / \mathrm{lit}$ & $\mathrm{ML}^{-3}$ \\
\hline
\end{tabular}

The final unknowns in the above equation are $a, c$, $d, e, f$ and $g$. The correlation 4 is the main equation of mass transfer flux in the absorption processes of carbon dioxide, which is not limited to the type of the solvent or the operation conditions. In correlation 4, both liquid and gas phase operating variables were combined to calculate the mass transfer flux.

\section{Mass transfer with chemical reaction}

In the absorption of $\mathrm{CO}_{2}$ into MEA solution, the molecular and ionic species are distributed by the reactions as shown in Figure 1.

When $\mathrm{CO}_{2}$ is absorbed in MEA solutions, some chemical reactions happen in the liquid phase. The following equilibriums for the chemical species in the liquid phase were used in the model to predict $\mathrm{CO}_{2}$ solubility ${ }^{22}$ :

$2 \mathrm{H}_{2} \mathrm{O} \stackrel{\mathrm{K}_{1}}{\longleftrightarrow} \mathrm{H}_{3} \mathrm{O}^{+}+\mathrm{OH}^{-}$

$2 \mathrm{H}_{2} \mathrm{O}+\mathrm{CO}_{2} \stackrel{\mathrm{K}_{2}}{\longleftrightarrow} \mathrm{HCO}_{3}^{-}+\mathrm{H}_{3} \mathrm{O}^{+}$

$\mathrm{H}_{2} \mathrm{O}+\mathrm{HCO}_{3}^{-} \stackrel{\mathrm{K}_{3}}{\longleftrightarrow} \mathrm{CO}_{3}^{2-}+\mathrm{H}_{3} \mathrm{O}^{+}$

$\mathrm{MEAH}+\mathrm{H}_{2} \mathrm{O} \stackrel{\mathrm{K}_{4}}{\longleftrightarrow} \mathrm{MEA}+\mathrm{H}_{3} \mathrm{O}^{+}$

$\mathrm{MEACOO}+\mathrm{H}_{2} \mathrm{O} \stackrel{\mathrm{K}_{5}}{\longrightarrow} \mathrm{MEA}+\mathrm{HCO}_{3}^{-}$

The condition of chemical equilibrium for a chemical reaction $\mathrm{R}$ is defined by eq. 10 :

$K_{R}(T)=\prod_{i} a_{i}^{v_{I, R}}, \mathrm{R}=(1$ to 5$)$

Constants for calculation of the various $K_{R}$ as a function of temperature are given in Table 2.

In addition to the above equilibrium equations, overall MEA and $\mathrm{CO}_{2}$ concentrations, as well as charge balance, must be satisfied:
$\begin{array}{cll}\mathrm{MEA} & \mathrm{CO}_{2} & \mathrm{H}_{2} \mathrm{O}\end{array}$

Vapor

$----------\mathbb{\Downarrow}-------\Uparrow------\Uparrow-----$

Liquid

$\begin{array}{ccc}\mathrm{MEA} & \mathrm{CO}_{2} & \mathrm{H}_{2} \mathrm{O} \\ \mathrm{MEAH} \mathrm{H}^{+} & \mathrm{HCO}_{3}^{-} & \mathrm{OH}^{-} \\ \mathrm{MEACOO} & \mathrm{CO}_{3}^{-2} & \mathrm{H}^{+} \\ & \mathrm{MEACOO} & \end{array}$

Figure 1. Vapor-liquid equilibrium system of $\mathrm{MEA}-\mathrm{CO}_{2}-\mathrm{H}_{2} \mathrm{O}$

$C_{M E A}=m_{M E A}+m_{M E A H^{+}}+m_{M E A C O O}$

$C_{\mathrm{CO}_{2}}=m_{\mathrm{CO}_{2}}+m_{\mathrm{HCO}_{3}^{-}}+m_{\mathrm{CO}_{3}^{2-}}+m_{\mathrm{MEACOO}^{-}}$

$m_{\mathrm{H}^{+}}+m_{\mathrm{MEAH}^{+}}=m_{\mathrm{OH}^{-}}+m_{\mathrm{HCO}_{3}^{-}}+2 m_{\mathrm{CO}_{3}^{2-}}+m_{\mathrm{MEACOO}^{-}}$

$\alpha=\frac{C_{\mathrm{CO}_{2}}}{C_{M E A}}$

$\alpha$ represents the ratio of absorbed $\mathrm{CO}_{2}$ to the MEA concentration. This parameter indicates the concentration effect of components on the abortion rate.

By solving this set of 8 independent equations (eqs. 10 to 13) for a given temperature, MEA overall concentration, and $\mathrm{CO}_{2}$ loading results in the true composition of the liquid phase, needed for solving the VLE equations. In order to calculate the parameters of the film, the reaction rate of $\mathrm{CO}_{2}$ in the MEA solution should be defined which is stated as eq. $17^{24}$.

$\mathrm{CO}_{2}+\mathrm{MEA}+\mathrm{H}_{2} \mathrm{O} \stackrel{k_{6}}{\longrightarrow} \mathrm{MEACOO}+\mathrm{H}_{3} \mathrm{O}^{+}$

$\mathrm{CO}_{2}+\mathrm{OH}^{-} \stackrel{k_{7}}{\longrightarrow} \mathrm{HCO}_{3}^{-}$

$r_{\mathrm{CO}_{2}}=r_{\mathrm{CO}_{2}, \mathrm{MEA}}+r_{\mathrm{CO}_{2}, \mathrm{OH}^{-}}=\left[k_{6}[\mathrm{MEA}]+k_{7}\left[\mathrm{OH}^{-}\right]\right]\left(\left[\mathrm{CO}_{2}\right]^{i}-\left[\mathrm{CO}_{2}\right]^{b}\right)$

Constants for calculation of $\mathrm{k}_{6}, \mathrm{k}_{7}$ as a function of temperature are given in Table 3 . The parameter $M$ is a film parameter which is used in mass transfer due to chemical reactions. Film parameter represents the mass transfer regime and the largeness of this number is an important criterion in the equipment design. Considering the definition of the film parameter (the ratio of the film conversion to the diffusion through the film), as the reaction zone close to the interface of the two films is higher, this parameter would be higher too. On the other hand, the less this parameter is, the reaction zone would transfer to the liquid bulk. The standard form of this parameter is defined as following equation ${ }^{\mathbf{2 4}}$ :

$M^{2}=\frac{D_{L} \times \sum_{i=1}^{2} r_{i, O_{2}}}{k_{L}^{2}\left[\mathrm{CO}_{2}\right]^{i}}=\frac{D_{L} \times\left[k_{6}[\mathrm{MEA}]+k_{7}\left[\mathrm{OH}^{-}\right]\right]\left(\left[\mathrm{CO}_{2}\right]^{i}-\left[\mathrm{CO}_{2}\right]^{b}\right)}{k_{L}^{2}\left[\mathrm{CO}_{2}\right]^{i}}$

Table 2. The equilibrium constants of equilibrium reactions of $\mathrm{MEA}-\mathrm{CO}_{2}-\mathrm{H}_{2} \mathrm{O}$ system ${ }^{23}$

\begin{tabular}{|l|c|r|r|r|}
\hline $\mathrm{K}_{\mathrm{R}}$ & $\mathrm{A}$ & $\mathrm{B}$ & $\mathrm{C}$ & $\mathrm{D}$ \\
\hline $\mathrm{K}_{1}$ & 132.890 & -13446.0 & -22.47 & 0.0000 \\
\hline $\mathrm{K}_{2}$ & 231.460 & -12092.0 & -36.78 & 0.0000 \\
\hline $\mathrm{K}_{3}$ & 216.050 & -12432.0 & -35.48 & 0.0000 \\
\hline $\mathrm{K}_{4}$ & -3.038 & -7008.3 & 0.00 & -0.0031 \\
\hline $\mathrm{K}_{5}$ & -0.520 & -2545.5 & 0.00 & 0.0000 \\
\hline \multicolumn{5}{|c|}{$\ln K_{j}=A_{j}+\frac{B_{j}}{T}+C_{j} \cdot \ln T+D_{j} \cdot T$} \\
\hline
\end{tabular}


Table 3. The constants of Arrhenius equation in the MEA solution $^{23}$

\begin{tabular}{|l|l|l|}
\hline $\mathrm{k}_{\mathrm{i}}$ & $\mathrm{A}\left[\mathrm{m}^{3} /(\mathrm{kmol} \cdot \mathrm{s})\right]$ & $\mathrm{E}[\mathrm{kJ} / \mathrm{mol}]$ \\
\hline 6 & $4.32 \times 10^{13}$ & 55.4603 \\
\hline 7 & $9.77 \times 10^{10}$ & 41.2564 \\
\hline \multicolumn{2}{|l|}{$k_{i}=A e^{\frac{-E}{R T}}$} \\
\hline
\end{tabular}

\section{Vapor-Liquid Equilibrium}

There are a wide variety of equilibrium models by which the solubility of acid gases in alkanolamines is predicted. Of the basic and simple models, the Kent and Eisenberg model can be named in which the equilibrium partial pressure of $\mathrm{CO}_{2}$ and $\mathrm{H}_{2} \mathrm{~S}$ in aqueous solutions of MEA and DEA is calculated ${ }^{24}$. In this model, the activity coefficients are assumed as 1 and the equilibrium constants of amine protonation reaction and boromite production reaction are used as an adjustable parameter to correlate the model with the experimental data. This model has limited functionality interpolation. Furthermore, it is less complex compared to other models and has simpler calculations. The results showed that in the loading range of 2.0 to 7.0, the model has a good accuracy. In fact, Kent and Eisenberg's model is based on the assumption that the liquid and vapor phases are considered ideal and non-ideal aspects of the system are gathered in equilibrium constants of reaction ${ }^{24}$. According to the mentioned research, the provided relationship suggested by Kent and Eisenberg is a simple but successful model for the loading of 1 (moles of acidic gas to moles of amine) in the range of 2.0 to 7.0 acid gases mole per amine mole and out of this range the model is not accurate enough. This model is not perfect theoretically because the effect of forces between the particles in solution is not considered directly. However, it has been accepted by many other authors due to its simplicity and good ability to predict the experimental data ${ }^{\mathbf{2 4}, \mathbf{2 5}}$.

In this work, only water is treated as a solvent species. $\mathrm{CO}_{2}$, Monoethanolamine, and the several ions are treated as solute species. The extended Raoult's law is used to express the VLE for water eq. 19, and the extended Henry's law is applied to obtain the equilibrium for $\mathrm{CO}_{2}$ eq. 20. It is assumed that water and $\mathrm{CO}_{2}$ at the interface of two phases in equilibrium and evaporation of amine and transfers it to the gas phase is neglected.

$P_{w}^{s a t} \varphi_{w}^{s a t} \exp \left[\frac{V_{w}\left(P_{t}-P_{w}^{s a t}\right)}{R T}\right] a_{w}=P_{t} y_{w} \varphi_{w}$

$m_{\mathrm{CO}_{2}} \gamma_{\mathrm{CO}_{2}} \mathrm{H}_{\mathrm{CO}_{2}, \mathrm{H}_{2} \mathrm{O}} \exp \left(\frac{v_{\mathrm{CO}_{2}, \mathrm{H}_{2} \mathrm{O}}^{\infty}\left(P_{t}-P_{w}^{s a t}\right)}{R T}\right)=P_{t} y_{\mathrm{CO}_{2}} \varphi_{\mathrm{CO}_{2}}$

In the calculation of VLE data, the following properties are required:

Henry's constants for the solubility of carbon dioxide in pure water, $\mathrm{H}_{\mathrm{CO}_{2}, \mathrm{H}_{2} \mathrm{O}}$, were taken from Rumpf and Maurer $^{23}$.

The vapor pressure $P_{w}^{s a t}$ and the molar volume $V_{w}$ of pure water were taken from Saul and Wagner ${ }^{26}$.

The fugacity coefficients $\varphi_{\mathrm{i}}$ were calculated using the Virial equation of state. Pure component second Virial coefficients $B_{\mathrm{H}_{2} \mathrm{O}, \mathrm{H}_{2} \mathrm{O}}$ and $B_{\mathrm{CO}_{2}, \mathrm{CO}_{2}}$ for water and carbon dioxide, respectively, were calculated on the basis of the data given by Dymond and Smith ${ }^{27}$. The mixed second Virial coefficients $H_{\mathrm{CO}_{2}, \mathrm{H}_{2} \mathrm{O}}$ were calculated according to the correlations of Hayden and O'Connell ${ }^{28}$.

The partial molar volume $v_{\mathrm{CO}_{2}, \mathrm{H}_{2} \mathrm{O}}^{\infty}$ of carbon dioxide dissolved at infinite dilution in water was calculated as recommended by Brelvi and O'Connell ${ }^{29}$.

\section{Extended UNIQUAC $\mathbf{G}^{\mathrm{E}}$ Model for Activity Coefficients}

The activity coefficients of both molecular and ionic species were calculated using the extended-UNIQUAC model for the excess Gibbs energy. The UNIQUAC model was modified using an electrostatic term presented by Sanders et $\mathrm{al}^{\mathbf{3 0}}$. The model framework implemented is presented by Thomsen and Rasmussen ${ }^{31}$. The model was constructed based on a combinatorial, entropic; a residual, enthalpic and the electrostatic of Debye-Huckel type terms ${ }^{31}$.

$\frac{g^{E}}{R T}=\left[\frac{g^{E}}{R T}\right]_{\text {Combinatorial }}+\left[\frac{g^{E}}{R T}\right]_{\text {Re sidual }}+\left[\frac{g^{E}}{R T}\right]_{\text {Debye-Huckel }}$

The activity coefficients of ions are:

$\ln \gamma_{i}^{D H}=-z_{i}^{2} A I^{1 / 2} /\left(1+\mathrm{b} I^{1 / 2}\right)$

The corresponding term for water is:

$\ln \gamma_{w}^{D H}=M_{W} 2 A\left[1+\mathrm{b} I^{1 / 2}-\left(1+\mathrm{b} I^{1 / 2}\right)^{-1}-2 \ln \left(1+\mathrm{b} I^{1 / 2}\right)\right] / b^{3}$

Where $\mathrm{M}_{\mathrm{w}}$ is the molar mass of water $\left(\mathrm{kg} \cdot \mathrm{mol}^{-1}\right)$, $\mathrm{b}=1.5\left(\mathrm{~kg} \cdot \mathrm{mol}^{-1}\right)^{1 / 2}$ is a constant and $D H$ is DebyeHückel parameter presented as follow ${ }^{23}$ :

$D H=\left[1.131+1.335 \times 10^{-3}(T-273.15)+1.164 \times 10^{-5}\right.$

$\left.(T-273.15)^{2}\right]\left(\mathrm{kg} \cdot \mathrm{mol}^{-1}\right)^{1 / 2}$

The combinatorial contribution to the activity coefficient of component $i$ is:

$\ln \gamma_{i}^{C}=\ln \left(\phi_{i} / x_{i}\right)+1-\phi_{i} / x_{i}-5 q_{i}\left[\ln \left(\phi_{i} / \theta_{i}\right)+1-\phi_{i} / \theta_{i}\right]$

Where $x_{i}$ is the mole fraction, $\varphi_{i}$ is the volume fraction, and $\theta_{i}$ is the surface area fraction of component $i$. The volume and surface area fractions of component $i$ are calculated as $^{32}$ :

$\phi_{i}=x_{i} r_{i} / \sum_{j} x_{j} r_{j} \quad \theta_{i}=x_{i} q_{i} / \sum_{j} x_{j} q_{j}$

The residual contribution to the activity coefficients is obtained:

$\ln \gamma_{i}^{R}=q_{i}\left[1-\ln \left(\sum_{l} \theta_{l} \psi_{l i}\right)-\sum_{j}\left(\theta_{j} \psi_{i j} / \sum_{l} \theta_{l} \psi_{l j}\right)\right]$

Where $\psi_{j i}$ is defined by the equation 28 as follow:

$\psi_{j i}=\exp \left[-\left(u_{j i}-u_{i i}\right) / T\right]$

The interaction energy parameters of $u_{j i}$ and $u_{i i}$ are independent of composition, but are temperature dependent:

$u_{j i}=u_{j i}^{0}+u_{j i}^{t}(\mathrm{~T}-298.15)$

The combinatorial activity coefficient at infinite dilution is ${ }^{31}$.

$\ln \left(\gamma_{i}^{C, \infty}\right)=\ln \left(\frac{r_{i}}{r_{w}}\right)+1-\frac{r_{i}}{r_{w}}-\left(\frac{z}{2}\right) q_{i}\left[\ln \left(\frac{r_{i} q_{w}}{r_{w} q_{i}}\right)+1-\frac{r_{i} q_{w}}{r_{w} q_{i}}\right]$ 
The corresponding term for residual is:

$\ln \left(\gamma_{i}^{R, \infty}\right)=q_{i}\left[1-\ln \psi_{w i}-\psi_{w i}\right]$

Finally, the expression for the solute activity coefficient is:

$\ln \gamma_{i}=\ln \left(\gamma_{i}^{C} / \gamma_{i}^{C, \infty}\right)+\ln \left(\gamma_{i}^{R} / \gamma_{i}^{R, \infty}\right)+\ln \gamma_{i}^{D-H}$

The expression for the solvent (water) activity coefficient is simply ${ }^{\mathbf{3 0}}$ :

$\ln \gamma_{w}=\ln \gamma_{w}^{C}+\ln \gamma_{w}^{R}+\ln \gamma_{w}^{D-H}$

The extended UNIQUAC model parameters including volume, $\mathrm{r}$ and the surface area, $\mathrm{q}$ parameters are given in Table 4. Also, the UNIQUAC interaction parameters were used from the literature ${ }^{\mathbf{3 2}}$.

Table 4. The UNIQUAC model parameters ${ }^{31,32}$

\begin{tabular}{|l|c|c|}
\hline Species & $\mathrm{r}$ & $\mathrm{q}$ \\
\hline $\mathrm{H}_{2} \mathrm{O}$ & 0.920 & 1.400 \\
\hline $\mathrm{MEA}$ & 4.280 & 4.280 \\
\hline $\mathrm{CO}_{2}$ & 5.741 & 6.081 \\
\hline $\mathrm{H}_{3} \mathrm{O}^{+}$ & 0.138 & 0.000 \\
\hline $\mathrm{MEAH}^{+}$ & 1.024 & 2.515 \\
\hline $\mathrm{OH}^{-}$ & 9.397 & 8.817 \\
\hline $\mathrm{HCO}_{3}^{-}$ & 9.157 & 6.346 \\
\hline $\mathrm{CO}_{3}^{2-}$ & 9.745 & 6.461 \\
\hline $\mathrm{MEACOO}^{-}$ & 1.074 & 0.111 \\
\hline
\end{tabular}

The experimental data presented in the literature was used to evaluate the present work results ${ }^{33}$. The experimental data range used in calculating the constants of mass transfer flux equation is shown in Table 5.

The following correlation constants were obtained in the MEA solution employing the presented dimensionless parameters:

$N_{\mathrm{CO}_{2}}=7.61 \times k_{L}\left(\left[\mathrm{CO}_{2}\right]^{i}-\left[\mathrm{CO}_{2}\right]^{b}\right)(\alpha)^{-3.944}\left(\frac{P_{\mathrm{CO}_{2}}}{P_{t}}\right)^{0.755}$

$\left(\frac{\delta_{g}}{\delta_{l}}\right)^{1.317}\left(\frac{D_{G}}{D_{L}}\right)^{0.619}(M)^{-0.706}$

The equation constants were determined by fitting the equation into the dimensionless parameters obtained from the experimental kinetics data ${ }^{\mathbf{3 0}}$. The Nelder-Mead numerical approach was used in the calculation of the correlation coefficients. This method attempts to minimize a nonlinear function of $\mathrm{N}$ real variables using only function values, without any derivative information. It is a heuristic search method that can converge to nonstationary points on problems that can be solved by alternative methods ${ }^{34}$.

\section{RESULTS AND DISCUSSION}

\section{Species concentrations}

In this study, a rigorous model (eq. 3) for the absorption rate of $\mathrm{CO}_{2}$ into MEA solution was presented. Besides, the effect of some operating parameters including free MEA, the enhancement factor, and the film parameter has been investigated. The effects of chemical reactions were also considered using the film parameter. Figure 2 shows the changes in the free MEA (molecular MEA) in the solution versus the $\mathrm{CO}_{2}$ loading. As it is evident from Figure 2, the more the loading factor is, the less the free MEA exists in the solution. Because, by increasing the loading factor, the amount of absorbed $\mathrm{CO}_{2}$ enhances too, showing that more MEA is reacted with $\mathrm{CO}_{2}$. Therefore, less free MEA exist in the solution.

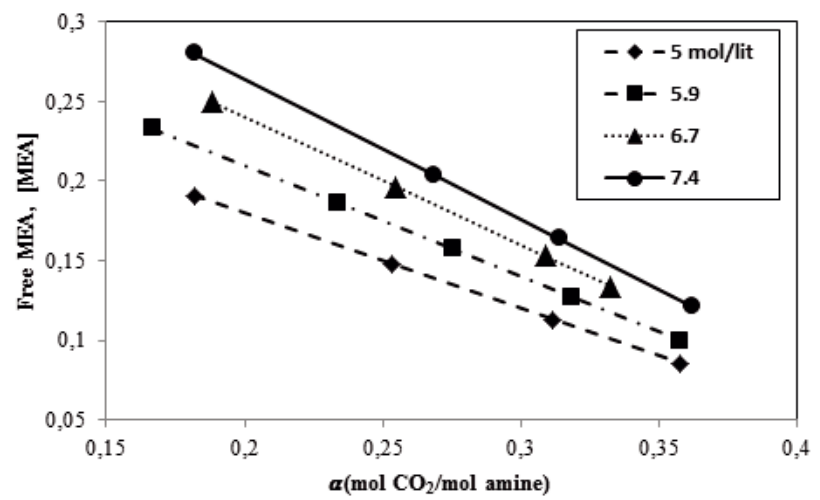

Figure 2. Variation of free MEA with $\mathrm{CO}_{2}$ loading at different MEA concentration

Figure 3 shows the variation of $\mathrm{MEAH}^{+}$with $\mathrm{CO}_{2}$ loading at different MEA solutions. It is clear that $\mathrm{MEAH}^{+}$was increased with increasing of MEA solution. According to eq. 15, increasing $\mathrm{CO}_{2}$ in MEA solution, produced $\mathrm{MEACOO}^{-}$and consequently as eq. 9, the concentration of free MEA was increased. Therefore based on eq. $8, \mathrm{MEAH}^{+}$will be increased the solution with high $\mathrm{CO}_{2}$ loading.

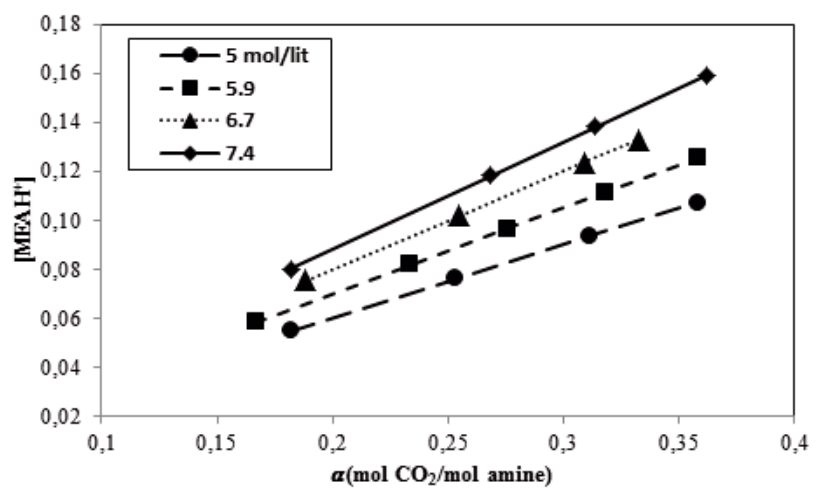

Figure 3. Variation of $\mathrm{MEAH}^{+}$concentration with $\mathrm{CO}_{2}$ loading at different MEA solution

Table 5. The operating condition of $\mathrm{CO}_{2}$ absorption process in MEA solution ${ }^{33}$

\begin{tabular}{|c|c|c|c|c|}
\hline $\begin{array}{c}\text { MEA } \\
\text { (molarity) }\end{array}$ & $\begin{array}{c}\text { Loading } \\
{\left[\mathrm{CO}_{2} / \mathrm{MEA}\right]}\end{array}$ & $\begin{array}{c}\mathrm{CO}_{2} \text { partial pressure } \\
{[\mathrm{kPa}]}\end{array}$ & $\begin{array}{c}\text { Total pressure } \\
{[\mathrm{kPa}]}\end{array}$ & $\begin{array}{c}\text { Temperature } \\
{\left[{ }^{\circ} \mathrm{C}\right]}\end{array}$ \\
\hline $5.0,5.9,6.7,7.4$ & $0.252-0.496$ & $0.017-38.519$ & $130-450$ & $40-100$ \\
\hline
\end{tabular}


Figure 4 indicates $\mathrm{HCO}_{3}^{-}$concentration at different MEA solution with $\mathrm{CO}_{2}$ loading. It is clear that $\mathrm{HCO}_{3}^{-}$ was increased with increasing $\mathrm{CO}_{2}$ at MEA solutions. Also based on eq. $9, \mathrm{HCO}_{3}{ }^{-}$was reduced by increasing MEA concentration.

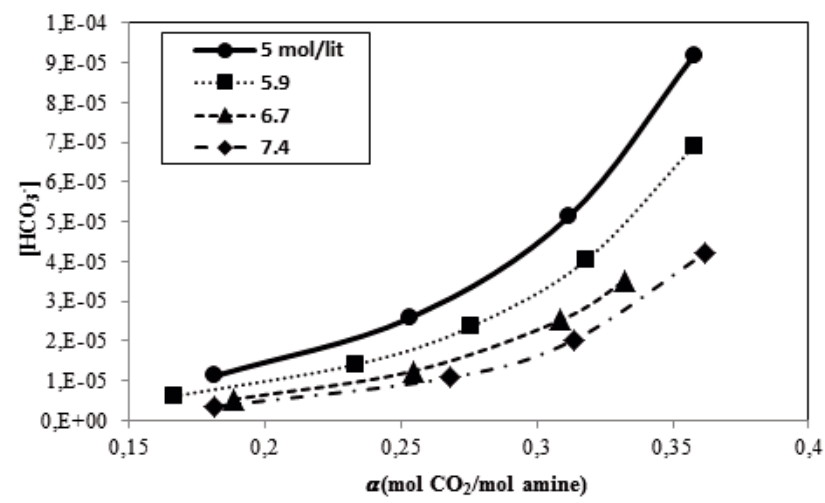

Figure 4. Variation on $\mathrm{HCO}_{3}^{-}$with $\mathrm{CO}_{2}$ loading at different MEA solution

Figure 5 indicates the basicity of MEA solution with $\mathrm{CO}_{2}$ loading. Due to the absorption of acidic gas $\left(\mathrm{CO}_{2}\right)$ the basicity of the solution decreases so acidity of the solution was increased.

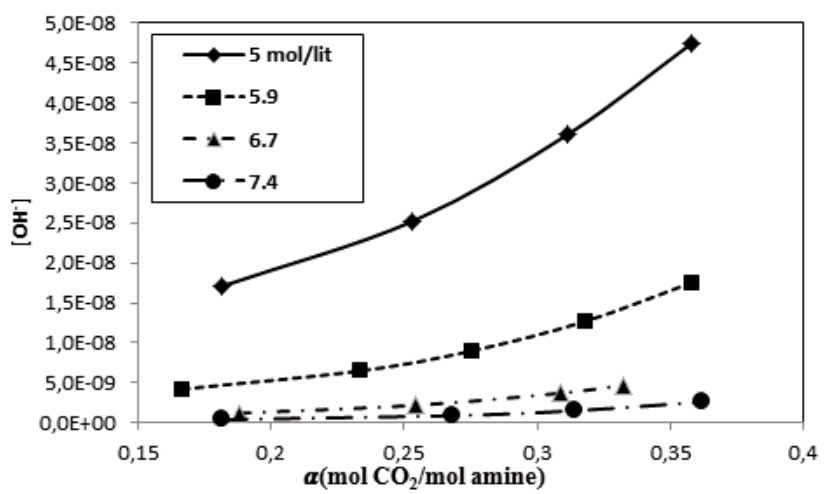

Figure 5. The basicity of MEA solution at different concentration and $\mathrm{CO}_{2}$ loading

Figure 6 shows MEACOO- variation with $\mathrm{CO}_{2}$ loading and MEA concentration. According to eq. 15 , it is clear that, $\mathrm{MEACOO}^{-}$was produced with the reaction between $\mathrm{CO}_{2}$ and MEA. Therefore MEACOO was increased with increasing of $\mathrm{CO}_{2}$ loading and MEA concentration.

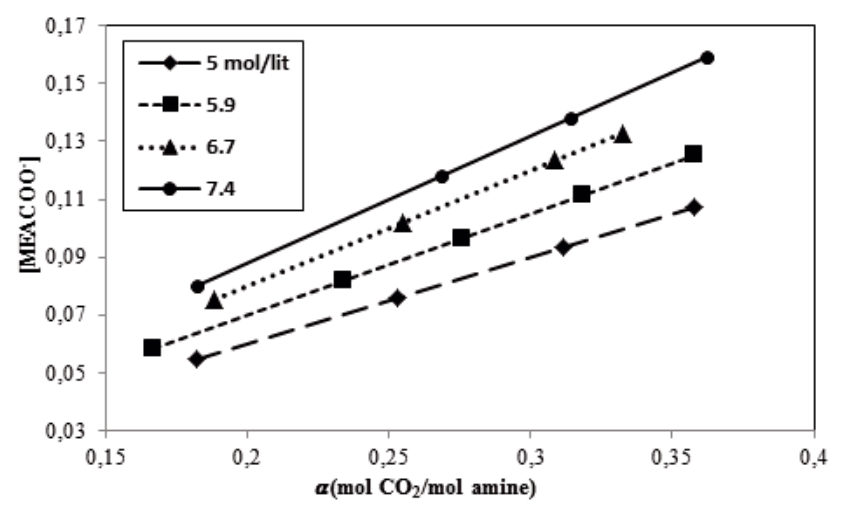

Figure 6. Variation of $\mathrm{MEACOO}^{-1}$ at different MEA solution with $\mathrm{CO}_{2}$ loading
Figure 7 shows $\mathrm{CO}_{3}{ }^{-2}$ concentration at different MEA solutions with $\mathrm{CO}_{2}$ loading. Due to eq. $6, \mathrm{HCO}_{3}{ }^{-}$was increased by increasing $\mathrm{CO}_{2}$ loading, therefore, $\mathrm{CO}_{3}{ }^{-2}$ was increased. Also, according to eq. 8, at high MEA concentration, $\mathrm{H}_{3} \mathrm{O}^{+}$was reduced and consequently $\mathrm{CO}_{3}^{-2}$ was increased based on eq. 7 .

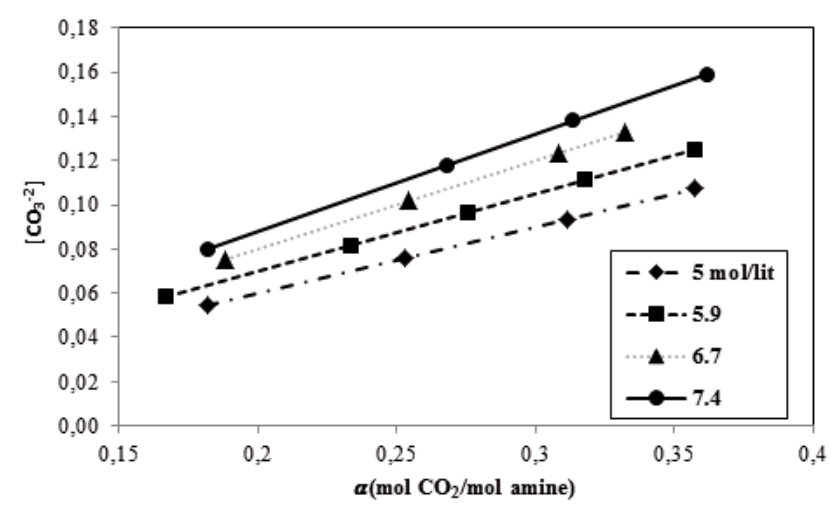

Figure 7. Variation of $\mathrm{CO}_{3}^{-2}$ at different MEA solution with $\mathrm{CO}_{2}$ loading

\section{Mass transfer parameters}

Figure 8 illustrates the enhancement factor versus the film parameter in different temperature. By raising the temperature, the enhancement factor decreases, showing that the absorption process is done much slower in these ranges. On the other hand, since the enhancement factor is proportional to the mass transfer flux and the absorption process is often an exothermic reaction, this flux declines too.

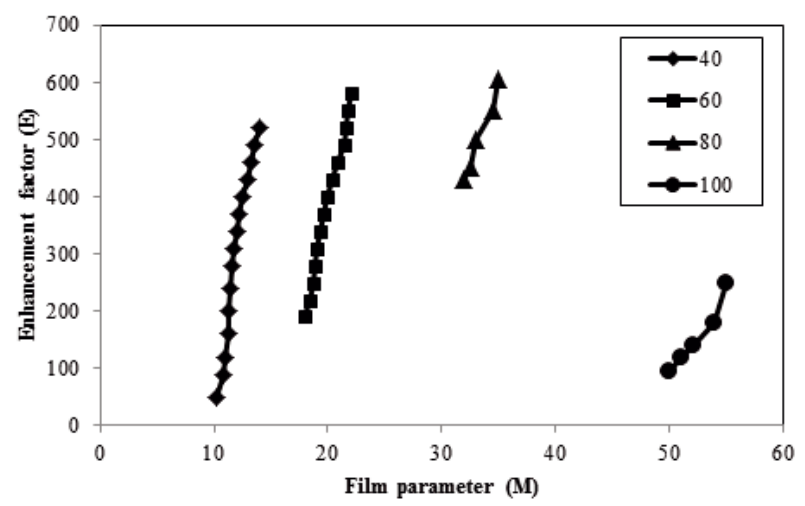

Figure 8. Effect of film parameter on enhancement factor at different temperatures

The trend of the film parameter against the $\mathrm{CO}_{2}$ loading in four different temperatures is shown in Figure 9. It is clear that, when the temperature is constant, solutions with lower loadings have higher film parameter values. Moreover, in a constant loading, an increase in temperature results in the enhancement of the film parameter. Furthermore, since the power of this parameter is minus in the eq. 34 and the absorption process is exothermic, the mass transfer fluxes decrease, consequently.

In Figure 10, the mass transfer flux of $\mathrm{CO}_{2}$ versus the loading in different film parameters are shown. As it is evident, low loadings represent that less carbon dioxide exists in the solvent before its injection to the absorption tower. In other words, the solvent is fresh. Thus, the driving force (the concentration difference) intensifies which further results in an increase in the mass transfer 


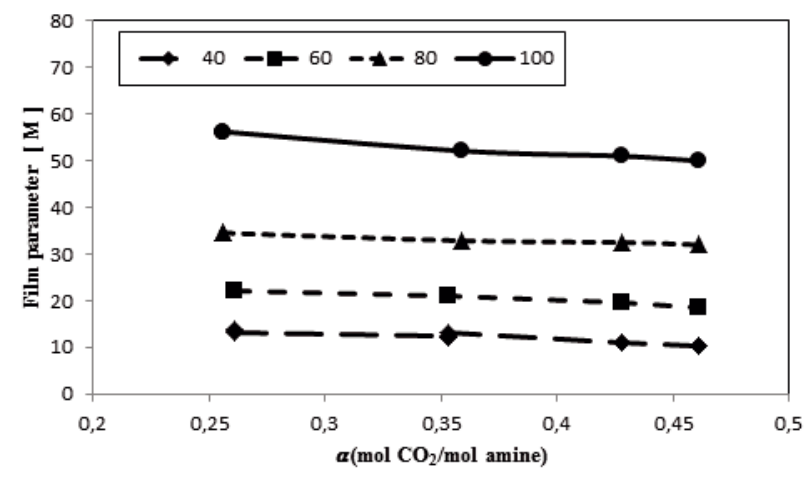

Figure 9. Variation of conversion film parameter with $\mathrm{CO}_{2}$ loading at different temperatures

flux. In fact, it is clear that the mass transfer flux and the loading are inversely proportional. On the other hand, as the film parameter rises, the mass transfer flux drops. However, in large values of the film parameter, the effect of this parameter on the mass transfer flux fades gradually.

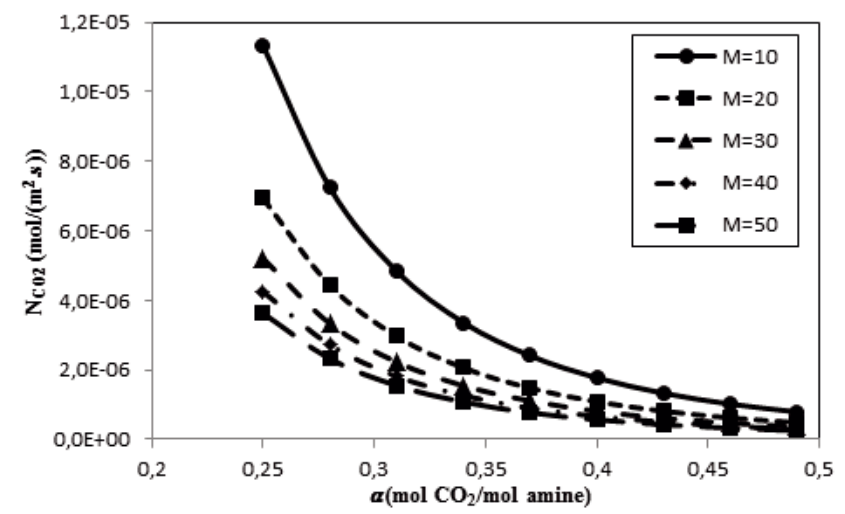

Figure 10. Effect of $\mathrm{CO}_{2}$ loading and film parameters on $\mathrm{CO}_{2}$ mass transfer flux

Figures 11 indicates the variation of $\mathrm{CO}_{2}$ mass transfer flux with $\mathrm{CO}_{2}$ loading and film parameter. It is clear that at low $\mathrm{CO}_{2}$ loading and film parameter $\mathrm{CO}_{2}$ mass flux is high. When $\mathrm{CO}_{2}$ loading is low, it means that the MEA solution is fresh and it has high capacity for $\mathrm{CO}_{2}$ absorption. The results show that film parameter is effective than $\mathrm{CO}_{2}$ loading on $\mathrm{CO}_{2}$ absorption (eq. 34).

In order to check the validity of the results obtained from the eq. 34, the average absolute error was calcu-

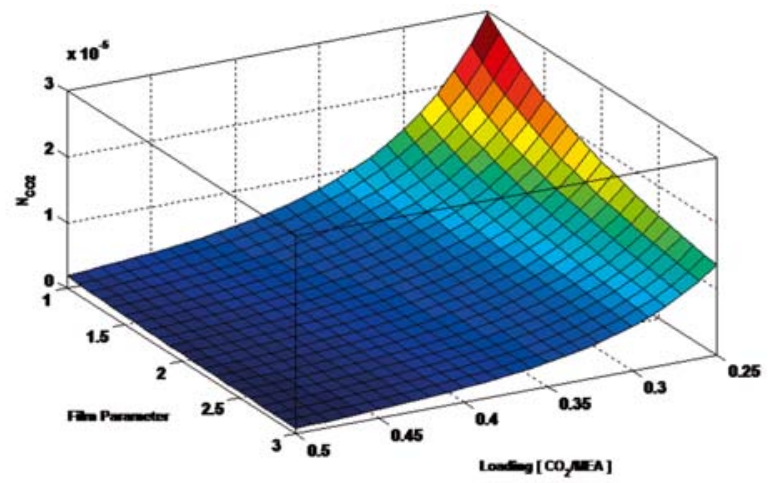

Figure 11. Mass transfer flux variation with $\mathrm{CO}_{2}$ loading and film parameter lated which gained $6.4 \%$, indicating that this equation is highly accurate to compare with previous correlations. Besides, the correlation coefficient $\left(\mathrm{R}^{2}\right)$ is illustrated in Figures 12.

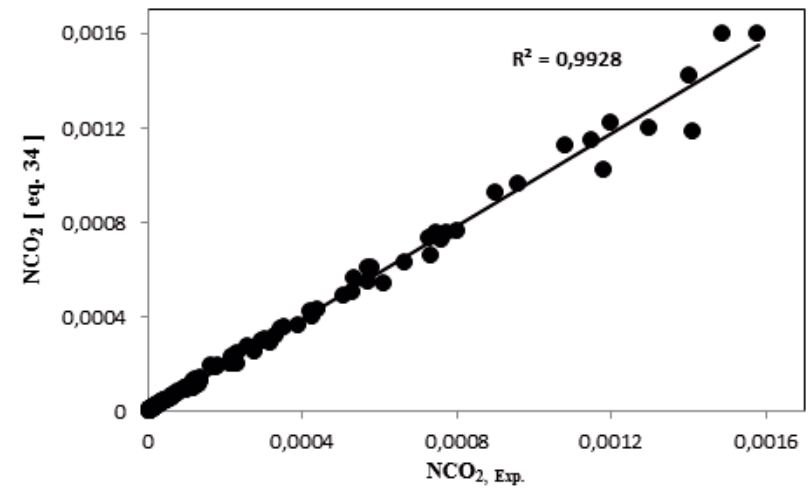

Figure 12. Predicted mass transfer flux using eq. 34 versus experimental data

\section{CONCLUSIONS}

Since the kinetics and the absorption rate of absorbents are of crucial importance in the design and modeling of equipment, in this research, the rate of carbon dioxide absorption in the MEA solution was investigated theoretically. A general rigorous correlation based on Etemad et al. approach ${ }^{\mathbf{2 1}}$ was suggested using the contributing parameters on the reactive absorption processes. Furthermore, these parameters, including loading factor, the ratio of $\mathrm{CO}_{2}$ partial pressure to the total pressure, the ratio of $\mathrm{CO}_{2}$ diffusion into the gas phase to the liquid phase, the ratio of film thickness in the gas phase to the liquid phase and the film parameter were made dimensionless using Pi-Buckingham method. It is worth to mention that in the suggested correlation, all the variables in both gas and liquid phase were applied. Also, all the chemical reactions occurred in the solution were considered in the mass transfer flux. In fact, the suggested correlation is a general term and is applicable for different processes at different operating conditions. Besides, the average absolute error of the relation was obtained as $6.4 \%$, indicating the high accuracy of the present correlation.

\section{NOMENCLATURE}

a, b, c, d, e, f - The Constants of eq. 3

$\mathrm{B}_{\mathrm{i}}-$ Virial coefficient of species $\mathrm{i}$

$\left[\mathrm{CO}_{2}\right]^{i} \quad$ - Interfacial concentration of dissolved $\mathrm{CO}_{2}$ $\left(\mathrm{mol} / \mathrm{m}^{3}\right)$

$\mathrm{C}_{\mathrm{CO}_{2}} \quad-$ Total $\mathrm{CO}_{2}$ concentration $\left(\mathrm{mol} / \mathrm{m}^{3}\right)$

$\left[\mathrm{CO}_{2}\right]^{b}-$ Concentration of $\mathrm{CO}_{2}$ in liquid phase $\left(\mathrm{mol} / \mathrm{m}^{3}\right)$

$C_{a \min b} \quad-$ Amine concentration $\left(\mathrm{mol} / \mathrm{m}^{3}\right)$

$C_{M E A} \quad-$ Total MEA concentration $\left(\mathrm{mol} / \mathrm{m}^{3}\right)$

$D_{G} \quad-\mathrm{CO}_{2}$ diffusion coefficient in gas phase $\left(\mathrm{m}^{2} / \mathrm{s}\right)$

$\mathrm{DH} \quad-$ Debye-Hückel parameter

$D_{L}-\mathrm{CO}_{2}$ diffusion coefficient in gas phase $\left(\mathrm{m}^{2} / \mathrm{s}\right)$

E - - Enhancement factor (dimensionless)

$g^{E} \quad-$ Excess Gibbs energy

$\mathrm{H}_{\mathrm{CO}_{2}, \mathrm{H}_{2} \mathrm{O}} \quad$ - Henry's constant for the solubility of $\mathrm{CO}_{2}$ in Pure water on the molality scale 
K

$\begin{array}{ll}k L & - \text { Liquid side mass transfer coefficient }(\mathrm{m} / \mathrm{s}) \\ m_{i} & - \text { Concentration of species i }\left(\mathrm{mol} / \mathrm{m}^{3}\right) \\ M & -\mathrm{CO}_{2} \text { film conversion parameter }(\text { dimen- } \\ \text { sionless) } & \end{array}$

$\begin{array}{lll}M_{w} & - \text { Water molecular weight }\left(\mathrm{kg} \cdot \mathrm{mol}^{-1}\right)\end{array}$

$N_{\mathrm{CO}_{2}}-\mathrm{CO}_{2}$ absorption rate $\left(\mathrm{mol} / \mathrm{m}^{2} \cdot \mathrm{s}\right)$

$P_{\mathrm{CO}_{2}}, \quad$ - Partial pressure of $\mathrm{CO}_{2}(\mathrm{~Pa})$

$P_{t} \quad-$ Total system pressure $(\mathrm{Pa})$

$P_{w}^{\text {sat }} \quad-$ Saturated vapor pressure of water $(\mathrm{Pa})$

$r_{i} \quad-$ Reaction rate of $\mathrm{i}\left(\mathrm{mol} / \mathrm{m}^{3} \cdot \mathrm{s}\right)$

$R \quad$ - The Gas constant $\left(8.314 \mathrm{~kJ} \mathrm{~K}^{-1} \mathrm{kmol}^{-1}\right)$

Sh $\quad-$ Sherwood number (dimensionless)

$T$ - Temperature (K)

$y_{\mathrm{CO}_{2}} \quad-$ Vapor phase mole fraction of $\mathrm{CO}_{2}$ (dimensionless)

$z_{i} \quad-$ Charge of ion $\mathrm{i}$

\section{Greek letters}

$\beta_{i, j}^{0,1}$

- $\mathrm{CO}_{2}$ loading ( $\mathrm{mol} \mathrm{CO} / \mathrm{mol}$ amine)

- Binary interaction parameters between species $i$ and $j$ in Pitzer's equation

$\gamma_{i} \quad-$ Activity coefficient of component i

$\delta_{g} \quad-$ Liquid film thickness $(\mathrm{m})$

$\delta_{l} \quad-$ Gas film thickness $(\mathrm{m})$

$\lambda_{i j} \quad-$ Second Virial coefficient in Pitzer's equa-

tion

$\varphi_{\mathrm{CO}_{2}} \quad-\mathrm{CO}_{2}$ fugacity coefficient

\section{LITERATURE CITED}

1. Bougie, F. \& Iliuta, M.C. (2011). $\mathrm{CO}_{2}$ Absorption in Aqueous Piperazine Solutions: Experimental Study and Modeling, J. Chem. Eng. 56, 1547-1554. DOI: 10.1021/je1012247.

2. Kohl, A.L. \& Nielsen, R.B., Gas Purification, 5th ed., Gulf Publishing Co., Houston, U.S.A., 1997.

3. Charkravarty, T. \& Phuken, U.K. (1985). Reaction of acid gases with mixtures of amines. Chem. Eng. Prog. 40, 32-36.

4. Pashaei, P., Nasiri, M. \& Ghaemi, A. (2017). Experimental study and modeling of $\mathrm{CO}_{2}$ absorption into diethanolamine solutions using stirrer bubble column. Chem. Eng. Res. Design 121, 32-43. DOI: 10.1016/j.cherd.2017.03.001.

5. Norouzbahari, S., Shahhosseini, Sh. \& Ghaemi, A. (2015). Modeling of $\mathrm{CO}_{2}$ loading in aqueous solutions of piperazine: Application of an enhanced artificial neural network algorithm. J. Nat. Gas Sci. Eng. 24, 18-25. DOI: 10.1016/j.jngse.2015.03.011.

6. Ghaemi, A., Shahhosseini, Sh. \& Maragheh, MG. (2009). Nonequilibrium dynamic modeling of carbon dioxide absorption by partially carbonated ammonia solutions. Chem. Eng. J. 149 (1), 110-117. DOI: 10.1016/j.cej.2008.10.020.

7. Nwaoha, C., Saiwan, C., Tontiwachwuthikul, P. \& Supap, T., Rongwong W., Idem R., AL-Marri M.J. \& Benamor, A. (2016). Carbon dioxide capture: Absorption-desorption capabilities of 2-amino-2-methyl-1-propanol (AMP), piperazine (PZ) and monoethanolamine (MEA) tri-solvent blends. J. Nat. Gas Sci. Eng. 33, 742-750. DOI: 10.1016/j.jngse.2016.06.002.

8. Pal, P., Abu Kashabeh, A., Al-Asheh, S. \& Banat, F. (2015). Role of aqueous methyldiethanolamine (MDEA) as solvent in natural gas sweetening unit and process contaminants with probable reaction pathway. J. Nat. Gas Sci. Eng. 24, 124-131. DOI: 10.1016/j.jngse.2015.03.007.

9. Qiu, K., Shang, J.F., Ozturk, M., Li, T.F., Chen, S.K., Zhang, L.Y. \& Gu, X.H. (2014). Studies of methyldiethanolamine process simulation and parameters optimization for high-sulfur gas sweetening. J. Nat. Gas Sci. Eng. 21, 379-385. DOI: $10.1016 /$ j.jngse.2014.08.023.

10. Øi, L.E. (2010). $\mathrm{CO}_{2}$ removal by absorption: challenges in modeling, Math Compu. Model. Dynamic Sys. 16, 511-33. DOI: $10.1080 / 13873954.2010 .491676$.

11. Boettinger, W., Maiwald, M. \& Hasse, H. (2008). Online NMR spectroscopic study of species 626 distribution in MEA$\mathrm{CO} 2-\mathrm{H} 2 \mathrm{O}$ and DEA- $\mathrm{H}_{2} \mathrm{O}-\mathrm{CO}_{2}$, Fluid Phase Equilibria. 263, 131-43. DOI: 10.1016/j.fluid.2007.09.017.

12. Pashaei, P., Ghaemi, A. \& Nasiri, M. (2016). Modeling and experimental study on the solubility and mass transfer of $\mathrm{CO}_{2}$ into aqueous DEA solution using a stirrer bubble column. RSC Adv. 6, 108075-108092. DOI: 10.1039/C6RA22589F.

13. Notz, R., Mangalapally, H.P. \& Hasse, H. (2012). Post combustion $\mathrm{CO}_{2}$ capture by reactive absorption: Pilot plant description and results of systematic studies with MEA. Int. J. Greenh. Gas Contr. 6, 84-112. DOI: 10.1016/j.ijggc.2011.11.004.

14. Lee, I.Y., Kwak, N.S., Lee, J.H., Jang, K.R. \& Shim, J.G. (2013). Oxidative Degradation of Alkanolamines with Inhibitors in $\mathrm{CO}_{2}$ Capture Process. Energy Proced. 37, 1830-1835. DOI:10.1016/j.egypro.2013.06.061.

15. Luis, P. (2016). Use of monoethanolamine (MEA) for $\mathrm{CO}_{2}$ capture in a global scenario: Consequences and alternatives. Desalination 380, 93-99. DOI: 10.1016/j.desal.2015.08.004.

16. Freguia, S. \& Rochelle, G.T. (2003). Modeling of $\mathrm{CO}_{2}$ Capture by Aqueous Monoethanolamine. AIChE J. 49, 1676-1686. DOI: 10.1002/aic.690490708.

17. Lv, B., Guo, B., Zhou, Z. \& Jing, G. (2015). Mechanisms of $\mathrm{CO}_{2}$ Capture into Monoethanolamine Solution with Different $\mathrm{CO}_{2}$ Loading during the Absorption/Desorption Processes. Environ. Sci. Technol. 49, 10728-10735. DOI: 10.1021/acs. est.5b02356.

18. Xie, H.B., Zhou, Y.Z., Zhang, Y.K. \& Johnson, J.K. (2010). Reaction mechanism of monoethanolamine with $\mathrm{CO}_{2}$ in aqueous solution from molecular modeling. J. Phys. Chem. A. 114, 11844-11852. DOI: 10.1021/jp107516k.

19. Wong, K., Bustam, M.A. \& Shariff, A.M. (2016). In situ measurement of physical solubility of carbon dioxide in loaded aqueous monoethanolamine by Raman spectroscopy. J. Nat. Gas Sci. Eng. 36, 305-313. DOI: 10.1016/j.jngse.2016.10.029.

20. Han, B., Zhou, C.G., Wu, J.P., Tempel, D.J. \& Cheng, H.S. (2011). Understanding $\mathrm{CO}_{2}$ capture mechanisms in aqueous monoethanolamine via first principles simulations. J. Physics Chem. Lett. 2, 522-526. DOI: 10.1021/jz200037s.

21. Etemad, E., Ghaemi, A. \& Shirvani, M. (2015). Rigorous correlation for $\mathrm{CO}_{2}$ mass transfer flux in reactive absorption processes. Int. J. Greenh. Gas Cont. 42, 288-295. DOI: 10.1016/j.ijggc.2015.08.011.

22. Moioli, S. \& Pellegrini, L.A. \& Gamba, S. (2012). Simulation of $\mathrm{CO}_{2}$ capture by MEA scrubbing with a ratebased model. Procedia Eng. 42, 1800-1810. DOI: 10.1016/j. proeng.2012.07.558.

23. Rumpf, B. \& Maurer, G. (1993). An Experimental and Theoretical Investigation on the Solubility of Carbon Dioxide in Aqueous Solutions of Strong Electrolytes. Ber. Bunsengesells. Physik. Chem. 97, 85-97. DOI: 10.1002/bbpc.19930970116.

24. Kent, R.L. \& Eisenberg, B. (1976). Better Data for Amine Treating, 87-90.

25. Ghaemi, A., Torab-Mostaedi, M., Ghannadi Maragheh, M. \& Shahhosseini, Sh. (2011). Kinetics and Absorption Rate of $\mathrm{CO}_{2}$ into Partially Carbonated Ammonia Solutions, Chem. Eng. Commun. 198, 1169-1181. DOI: 10.1080/00986445.2010.525204. 
26. Saul, A. \& Wagner, W. (1987). International Equations for the Saturation Properties of Ordinary Water Substance. J. Phys. Chem. 16, 893-901. DOI: 10.1063/1.555787 .

27. Dymond, J.H. \& Smith, E.B. The Virial Coefficients of Pure Gases and Mixtures, Oxford University Press: Oxford, UK, 1980.

28. Hayden, J.G. \& O'Connell, J.P. (1975). A Generalized Method for Predicting Second Virial Coefficients. Ind. Engi. Chem. Proc. Design Develop. 14, 209-216. DOI: 10.1021/ i260055a003.

29. Brelvi, S.W., O’Connell, J.P. (1972). Corresponding States Correlations for Liquid Compressibility and Partial Molal Volumes of Gases at Infinite Dilution in Liquids. AIChE J. 18, 1239-1243. DOI: 10.1002/aic.690180622.

30. Sander, B., Fredenslund, A. \& Rasmussen, P. (1986) Calculation of Vapor-Liquid Equilibrium in Mixed Solvent/ Salt Systems using an Extended UNIQUAC Equation, Chem. Eng. Sci. 41, 1171-1183. DOI: 10.1016/0009-2509(86)87090-7.

31. Thomsen, K. (2005). Modeling electrolyte solutions with the extended universal quasi chemical (UNIQUAC) model. Pure Appl. Chem. 77, 531-542. DOI: 10.1351/pac200577030531.

32. Aronu, U.E., Gondal, Sh., Hessen, E.T., Haug-Warberg, T., Hartono, A., Hoff, K.A. \& Svendsen, H.F., (2011). Solubility of $\mathrm{CO}_{2}$ in $15,30,45$ and 60 mass $\%$ MEA from 40 to $120^{\circ} \mathrm{C}$ and model representation using the extended UNIQUAC framework. Chem. Eng. Sci. 66, 6393-6406. DOI: 10.1016/j. ces.2011.08.042.

33. Dugass, R.E. (2009). Carbon Dioxide Absorption, Desorption, and Diffusion in Aqueous Piperazine and Monoethanolamine, PhD Dissertation, University of Texas at Austin.

34. Lagarias, J.C., Reeds, J.A., Wright, M.H. \& Wright, P.E. (1998). Convergence properties of the Nelder-Mead simplex method in low dimensions. SIAM J. Optim. 9, 112-147. DOI: $10.1137 / \mathrm{S} 1052623496303470$. 